\title{
Effective additive for foam concrete
}

\author{
Vladimir Belov ${ }^{1, *}$, and Pavel Kuliaev ${ }^{1}$ \\ ${ }^{1}$ Tver State Technical University, Civil Construction Department, 22, Af. Nikitin Quay, Tver, \\ 170026, Russia
}

\begin{abstract}
In search of a building material of the XXI-st century, architects, investors and builders are increasingly coming to one recently successfully approved solution - the use of foam concrete in construction, which, due to its exceptional characteristics, meets the multilateral requirements of the construction industry. The article presents the way to use technogenic wastes in the production of non-autoclave foam concrete.
\end{abstract}

\section{Introduction}

Foam concrete is characterized by high versatility, relative simplicity of technology, low production costs in the manufacture of products. This is owing to the fact that the production of concrete in a wide range of density values is possible on the same equipment by using natural sand as a filler. Due to the simplicity of the technology and the equipment used (when excluding grinding raw materials in ball mills from the technological cycle and autoclave processing), the cost of products is 1.5-2 times lower than the cost of the same products made of cellular aerated concrete.

The possibility of excluding foam concrete from the heat treatment technology ensures that it can be effectively used in monolithic construction. The density of foam concrete (using fine sand of natural dispersion as a filler) is usually within $600 \ldots 1000 \mathrm{~kg} / \mathrm{m} 3$, and the compressive strength is $1.5 \ldots 3.5 \mathrm{MPa}$ (concrete class 15...35). To obtain foam concrete with a lower average density with maintaining strength, ground sand is used, as well as hardening accelerators, reducing, water-reducing and other additives.

Sometimes, in order to reduce the density and eliminate the grinding operation, foam concrete is produced from cement binder without sand. This material is called foam cement. However, this concrete has essential shrinkage when drying, which reduces its quality indicators. All these difficulties prevent the foam concrete from widespread use altogether with a lack of of highly qualified specialists.

In the future, the most reasonable ways for small producers will be to use ready-made dry mixes for foam concrete, which will provide a significant improvement in its properties. In this case, the foam concrete mix will be prepared by professionals in advance, the materials of guaranteed quality being used. Manufacturers will have to put in the dry mixture some water according to the instructions. However, the practical implementation of this idea is a matter of the future.

\footnotetext{
Corresponding author: vladim-bel@ya.ru
} 
With regard to the most common products - wall blocks and stones made of foam concrete - practice has shown that they achieve an optimal ratio between the density and thermal conductivity of concrete, on the one hand, and its strength and frost resistance, on the other. The use of foam concrete as a material for lightweight elements and fencing structures allows us to meet modern requirements for heat efficiency of residential buildings. Houses made of foam concrete allow to save natural and energy resources. They are distinguished by high quality, energy efficiency, low construction costs; they have a long service life. At the same time, it is important to reduce the wall thickness while maintaining its necessary thermal resistance, which can be achieved by reducing the average density of the material.

Currently, finely-ground limestone with a nanoscale component is used to modify and improve concrete properties [1]. This is due to the ability of fine-ground limestone to interact with concrete clinker components at the physical and partially chemical levels, forming a monolith $[2,3]$. The positive effect of carbonate fillers is explained by the fact that they have a chemical affinity with cement, which leads to the formation of a dense contact between them and the fusion of hydration products of cement with the filler during natural hardening. An important feature of limestone rocks is that they are not inert, but enter into an active physical and chemical interaction with clinker minerals of cement, participating in the formation of the structure of the cement stone.

In addition, it is known that finely ground limestone helps to reduce water segregation, water demand and delamination of the mixture, increase their water-holding capacity, plasticity, and also improves the water and frost resistance of the solution [4].

Physical and chemical compatibility of the nanosized component of finely-ground limestone with a binder and solid components of the concrete is technologically revealed in the following effects: powdering cement grains, micro-reinforcement of structure of cement stone and concrete, promoting the appearance of additional amount of cementitious formations. This positive effect of the carbonate microfiller is enhanced by a synergistic effect when optimizing the granulometry of the grain composition of the mineral part by implementing a model of the densest particle packages [5].

Thus, the use of a microdispersed limestone filler made of the crushed wastes of carbonate aggregates in combination with a superplasticizer as a complex additive in the manufacture of foam concrete in order to improve the operational and technological properties of this material, as well as increase its durability by forming a better microstructure of interstitial partitions is currently very actual for the construction industry.

Almost all types of natural-hardening foam concrete have low resistance to tensile stresses and increased brittleness, resulting in unwanted cut-chips and cracks. Nonautoclaved foam concrete is also characterized by high shrinkage, which leads to intensive cracking and even destruction of products. A radical way to eliminate these disadvantages is the dispersed reinforcement of foam concrete with fibers, which provides a significant improvement in the strength and deformative properties of the material, as well as increasing the operational reliability of products [6]. Dispersed-reinforced foam concrete is destroyed as a plastic material, without sudden opening of cracks and breakage into separate pieces. It is established that the putting of polymer fibers in foam concrete mixtures allows 2-2.5 times to increase the bending strength, and up to 1.5 times-the compressive strength. Fiber reinforcement completely eliminates the appearance and development of shrinkage cracks during the material hardening [7].

\section{Materials and technics}

In this paper, we studied the effect of a complex additive, including fine-grained limestone with a specific surface area of $310 \mathrm{~m} 2 / \mathrm{kg}$ according to PSC-2, superplasticizer C-3, a fiber 
component in the form of the utilized textile cord obtained during the processing of old tires, as well as a hardening accelerator, on the properties of foam concrete obtained by "dry mineralization" [8].

Foam concrete of "dry mineralization" was obtained in the form of cubes with a rib size of $100 \mathrm{~mm}$. The following basic raw materials were used: quartz sand with a grain size module; Portland cement of the PC-500 D0 class and foam agent FF-2000. The overdosed amount of water (based on $\mathrm{w} /$ solid $=0.64)$ was mixed in a vertical mixer $(1000 \mathrm{~min}-1)$ with the addition of $0.33 \%$ of the foaming agent for $3 \mathrm{~min}$, then with continuous mixing for 1 min (200 min-1), a dry mixture of cement, sand and a complex additive was evenly added to the foam in a ratio of 1: $0.18: 0.064$, respectively, the resulting homogeneous molding mixture was poured into molds. The samples were tempered at a temperature of $60^{\circ} \mathrm{C}$ for 3 days.

\section{Test results}

The analysis of the data obtained (table) shows that the use of the described additive with the same strength of foam concrete can reduce the average density of the material by 100 $\mathrm{kg} / \mathrm{m} 3$ and the coefficient of thermal conductivity by $13.3 \%$.

\begin{tabular}{|c|c|c|c|}
\hline $\begin{array}{c}\text { Composition of "dry } \\
\text { mineralization" foam } \\
\text { concrete }\end{array}$ & $\begin{array}{c}\text { Average density of } \\
\text { samples, } \mathbf{~ k g} / \mathbf{~ m}^{\mathbf{3}}\end{array}$ & $\begin{array}{c}\text { Average compressive } \\
\text { strength at the age of 3 } \\
\text { days, } \mathbf{M P a}\end{array}$ & $\begin{array}{c}\text { Coefficient of } \\
\text { thermal } \\
\text { conductivity, } \\
\mathbf{W} /\left(\mathbf{m}^{* \circ} \mathbf{C}\right)\end{array}$ \\
\hline Without additives & 600 & 1,2 & 0,15 \\
\hline With the addition & 500 & 1,2 & 0,13 \\
\hline
\end{tabular}

The introduction of a reinforcing fiber additive into foam concrete in an amount of 1-2 $\%$ increases its compressive strength by $20-44 \%$ at the same density compared to foam concrete without a fiber additive. Further increase in the concentration of utilized textile cord is not possible, since this leads to the formation of lumps of tangled fibers. This reduces the strength of the concrete.

The positive effect of fiber additives on the properties of foam concrete is explained by the following reasons. On the surface of the fibers, evenly distributed in the volume of the mixture, there are particles of the solid phase. The first which move to the extended phase separation surfaces (fibers) are the smallest of them, whose energy is regulated by the volume concentration of the liquid phase. The thickness of water films firmly bound to the surface of the solid phase is proportional to the size of the particles. Therefore, a variatropic structure of the concrete mix is naturally formed on the surface of the dispersed reinforcement, the ability of which to accumulate defects in the form of cracks is limited by geometric parameters and the amount of fiber.

Cellular concretes are three-phase dispersed systems. In such systems, stability and cohesion are provided when the capillary and wedging pressures of the film water in the capillary meniscus zones are balanced, as well as by surface tension forces [9]. The most significant factor that increases the strength of cellular concrete at a given density is the "reinforcing" of air cells with cement particles [8]. This " reinforcing " is essentially a manifestation of the processes of capillary structure formation, similar to globulation in raw mixes of building materials, provided a kind of inversion-the replacement of large aggregate grains with air (in foam concrete) or gas (in aerated concrete) cells. Considering this, a parameter of the optimal structure of cellular concrete is the maximum efficiency coefficient (in MPa), determined by the formula

$$
\mathrm{K}_{\text {eff }}=R_{\text {conp }} /\left(\rho_{\mathrm{o}}\right)^{2} \text {, }
$$


where $R_{\text {comp }}$ - compressive strength, $\mathrm{MPa} ; \rho_{\mathrm{o}}$ - the average density of cellular concrete in the dry state (relative to the density of water).

Based on the planned experiments application and optimization of the obtained mathematical models, which present the dependence of the average density, compressive strength and efficiency coefficient on the composition factors, the foam concrete composition was chosen that meets the requirements of GOST (State standards) 25485 for structural and heat-insulating non-autoclaved concrete of the average density D500 and compressive strength class B1.

\section{Summary and prospects}

The use of technogenic wastes in the production of non-autoclave foam concrete, such as limestone crushed waste and utilized textile cord, contributes to improving the performance properties of the material, while solving the environmental problems of the region, expanding the raw material base for the production of construction materials, as well as reducing the cost of production.

\section{References}

1. V.G. Khozin, O.V. Khokhryakov, Carbonate cements of low water demand, Technologies of concrete, 11-12, 25 (2009)

2. U. El Shamy, C. Denissen, Microscale energy dissipation mechanisms in cyclicallyloaded granular soils, Geotechnical and Geological Engineering, 30(2), 343-361 (2012)

3. G. De Schutter, Influence of limestone filler as a mineral additive in self-compacting concrete, Belgium Magnel laboratory of concrete research, 36 Conference on Our World in concrete \& Structures (Singapore, 14-16/08/, 2011)

4. I.A. Zinov, High-Strength concrete with the addition of micro-silica, Izvestiya vuzov. Construction and architecture, 4, 55 (1990)

5. B. Moser, C. Pfeifer, Microstructure and Durability of Ultra-High Performance Concrete, Proceedings of the Second International Symposium on Ultra High Performance Concrete Kassel (Germany March, 05-07, 2008)

6. L.V. Morgun, Efficiency of application of fibropenobetona in modern construction, Construction materials, 3, 16-17 (2002)

7. L.V. Morgun, V.N. Morgun, Influence of dispersed reinforcement on the aggregate stability of foam concrete mixtures, Construction materials, 1, 33 (2003)

8. A.P. Merkin, Cellular concrete scientific and practical prerequisites for further development, Construction materials, 2, 11-15 (1995)

9. V.V. Belov, Capillary autohesion in three-phase raw mixes, Fundamental, research and applied research of the Russian Academy of architecture and construction Sciences on scientific support for the development of architecture, urban planning and the construction industry of the Russian Federation in 2018 (Russian Academy of architecture and construction Sciences, Moscow, 58-68, 2019) 